\title{
Difference in Total Serum Immunoglobulin E Level Among Patients with and without Intravenous Contrast Media Adverse Reaction on Computed Tomography Scan Examination
}

\author{
Yulikha Ikhmawati ${ }^{*}$, Zuhrial Zubir ${ }^{2}$, Elvita Rahmi Daulay ${ }^{3}$ \\ ${ }^{1,2}$ Pulmonology and Allergy-Immunology Divison, Internal Medicine Department, Faculty of Medicine \\ Universitas Sumatera Utara, Indonesia \\ ${ }^{3}$ Radiology Department, Medical Faculty of Medicine Universitas Sumatera Utara, Indonesia
}

\begin{abstract}
Background: The adverse reaction (AR) to intravenous contrast media (ICM) are relatively common. Various opinions pro-posed in the mechanism of the incidence of ICM AR. Suspected that the role of Immunoglobulin E (IgE) me-diates allergic conditions that are part of the AR. Objective: To determine the difference in total serum IgE level among subjects with and without ICM AR on computed tomography (CT) scan examination. To observe difference in total serum IgE levels in subjects undergoing ICM adverse reaction based on the degree of severity. Method: An analytical study with cross-sectional design of 104 subjects undergoing CT scans with ICM, examined IgE levels before and after ICM was administered, then measured the severity of adverse re-actions of contrast media. Result: In this study, subjects undergoing adverse reactions, prior to administration Iopamidol had a higher mean IgE $1270.79 \mathrm{mg} / \mathrm{dl}$ compared with those who having AR $1174.90 \mathrm{mg} / \mathrm{dl}$ and after administration of Iopamidol a mean of Ig E is still higher in subjects having AR 1507.96 $\mathrm{mg} / \mathrm{dl}$ com-pared with those having negative AR that is $1325.88 \mathrm{mg} / \mathrm{dl}, \mathrm{p}=0.696$, statistically, not significant. Mild reac-tions in 40 subjects $(38.5 \%)$ with cough, nausea, dizziness, itching, and sweating. Conclusion: Increase in total $\operatorname{IgE}$ levels in subjects with positive adverse reactions are independent $(\mathrm{p}=0.696)$.
\end{abstract}

Keyword: Immunoglobulin E, Adverse Reaction, Intravenous Contrast Media

Received 29 December 2018 | Revised 16 January 2019 | Accepted 31 January 2019

*Corresponding author at: Faculty of Medicine, Universitas Sumatera Utara, Medan, Indonesia 


\section{Introduction}

Contrast media iodine is one of the most widely used drugs in the world. This substance was introduced into clinical practice in 1950, and since then about 75 million X-ray examinations have been per-formed yearly using contrast media. In addition, the number of patients receiving this drug continues to increase with increasing use of $\mathrm{CT}$ scans. Although these chemicals are inert and are considered relative-ly safe, hypersensitivity reactions may occur to con-trast media ranging from mild to severe, even life-threatening [1].

In radiological imaging, it is usually believed that the adverse reactions of intravenous (IV) iodinated con-trast media (ICM) are non-IgE mediated anaphylac-toid reactions, by the result of released vasoactive amines (histamine, serotonin, etc.) with the triggering of mast cells directly. But exact mechanism is still controversial [2]. The purpose of this study is to de-termine the igE levels in the blood in patients under-going CT scan with intravenous contrast, the relation between total igE levels and the reactions to contrast media.

\section{Methodology}

Cross sectional studies were conducted from November 2016 to Februari 2017, in RSUP Haji Adam Malik Medan, 208 blood samples were taken from 104 subjects between 17-78 years (mean,54 years) of age who underwent CT scan procedures with intrave-nous contrast media, in this study, used Iopamidol. The exclusion criteria were 1) pregnancy and lactation, 2) patients with chronic kidney disease, 3 ) patients with immunosuppressant for last 48 hours. Blood samples were taken from all 104 randomly se-lected patients. First just before administration of IV ICM, then at the 48th hours following the exam-ination. Total IgE levels in all the blood samples were calculated with VIDAS ${ }^{\circledR}$ by using ELISA method.

The subjects interviewed and asked about history of atopy in the families by fill in the questionnaire. Ear-ly and/or late reactions that were observed during and after administration IV ICM were classified as mild, moderate and severe according to Bush and Swanson's classification [3]. The normal value of IgE level was under $100 \mathrm{IU} / \mathrm{mL}$ according to the refer-ence value given by Dati and Ringel [4]. The result was analyzed by paired $t$ test, chi-square test and $t$ test.

\section{Results}

During the study, 104 subjects who met the inclusion criteria which 52 subjects were having history of atopy. Characteristics of the whole study subjects is presented on (Table 1). 
Adverse reactions that were observed in 40 (38.5\%) subjects were mild, no moderate and severe reac-tions were observed in any patient. Mild adverse reaction was cough 9 subjects (8.6\%), nausea 10 subjects $(9.6 \%)$, dizziness 10 subjects $(9.6 \%)$, itching 10 subjects $(9.6 \%)$, and sweating 1 subjects $(0.9 \%)$ (As shown in fig. 1$)$. Observed adverse reactions, were not correlate with total igE levels in the blood ac-cording to chi-square test $(\mathrm{p}=0.69)$ (As shown in Table 2).

Table 1 Characteristics of the Study Subjects

\begin{tabular}{ll}
\hline Characteristics & $\mathrm{n}=104$ \\
\hline Sex & $72(69,2 \%)$ \\
Male & $32(30,8 \%)$ \\
Female & $54,279( \pm 12,7)$ \\
Age, Mean (SD), Years & \\
Atopy history & $52(50 \%)$ \\
Atopi & $52(50 \%)$ \\
Non-atopi & $24(9-86)$ \\
Ureum, median (min-max), & \\
mg/dL & \\
Creatinin, median (min-max), & $0.78(0.13-1.77)$ \\
mg/dL & \\
Ig E pre-CT scan, median & $518,700(10-8693,0)$ \\
(min-max), U/L & \\
Ig E post CT scan, median & $721,500(25,0-9458,0)$ \\
(min-max), U/L & \\
\hline
\end{tabular}

Adverse reactions that were observed in 40 (38.5\%) subjects were mild, no moderate and severe reactions were observed in any patient. Mild adverse reaction was cough 9 subjects $(8.6 \%)$, nausea 10 subjects $(9.6 \%)$, dizziness 10 subjects $(9.6 \%)$, itching 10 sub-jects $(9.6 \%)$, and sweating 1 subjects (0.9\%). (As shown in Fig.1) Observed adverse reactions, were not correlate with total igE levels in the blood ac-cording to chi-square test $(\mathrm{p}=0.69)$. (As shown in Table 2 ).

Table 2 Mean and Median of Total Serum Ige Level in Subjects with and without Adverse

\begin{tabular}{llllll}
\hline $\begin{array}{l}\text { Adverse } \\
\text { reactions } \\
(\text { AR) }\end{array}$ & \multicolumn{5}{c}{ Total Serum IgE Level } \\
& Pre-CT scan & \multicolumn{3}{c}{ Post CT scan } & P \\
\cline { 2 - 5 } & Mean & $\begin{array}{l}\text { Std. } \\
\text { Deviatio } \\
\mathrm{n}\end{array}$ & Mean & $\begin{array}{l}\text { Std. } \\
\text { Deviati } \\
\text { on }\end{array}$ & \\
\hline Without & 1159.85 & 1479.349 & 1308.93 & 1670.86 & 0,69 \\
AR & 0 & 3 & 3 & 56 & 6 \\
$(\mathrm{n}=64)$ & & & & & \\
With AR & 1270.78 & 1787.465 & 1507.95 & 2052.36 & \\
$(\mathrm{n}=40)$ & 5 & 4 & 5 & 53 & \\
\hline
\end{tabular}

\begin{tabular}{l|llllll}
70 & & & & & \\
60 & & & & & \\
50 & & & & & \\
40 & & & & & \\
30 & 9 & 10 & 10 & 10 & 1 \\
20 & 9 & & &
\end{tabular}


Figure 1 Observed Adverse Reactions in Subjects of the Study

Table 3 Adverse Reaction in Subjects with Atopy and Non-Atopy After Administration IV ICM

\begin{tabular}{lllll}
\hline Subjects & \multicolumn{2}{l}{ Adverse reaction (AR) } & Total & $\mathrm{p}$ \\
\cline { 2 - 3 } & Without & With AR & & \\
& AR & & & \\
\hline Atopy & $30(58 \%)$ & $22(42 \%)$ & $52(100 \%)$ & $0.110^{*}$ \\
Non-atopy & $34(65 \%)$ & $18(35 \%)$ & $52(100 \%)$ & \\
Total & $64(61,5 \%)$ & 40 & 104 & \\
& & $(38,5 \%)$ & $(100 \%)$ & \\
\hline
\end{tabular}

*Chi square test

From Table 3, shown observed AR in $42 \%$ atopy subjects, and 35\% in non-atopy subjects. With Chi-square, $p=0.110$ showed no significantly difference on atopy with non-atopy in the observed adverse reaction after IV ICM.

\section{Discussion}

The results of this study shows the characteristics of the study subjects with positive adverse reactions were mostly male, 28 subjects (70\%); this is different from the findings of Dundee and colleagues who conducted research on atopy and allergy in 10,000 patients undergoing anesthesia, the results obtained, found an allergy in iodine with $0.8 \%$ in men and $1.4 \%$ in women. One of the causes of this difference that can be stated is the amount of sample differ-ence, where the number of samples with male sex dominates 72 people (69.2\%) of the total sample population [5].

Positive adverse reaction was found in atopy pa-tients by $42 \%$ compared with incidence in nonatopy patients of $35 \%$. This is in line with the results of a study conducted by Dundee and colleagues who obtained similar results, which encountered higher frequency of adverse reactions in patients with a history of atopy of $36.2 \%$ compared with patients who did not have a history of atopy of $11,4 \%[5]$.

This study obtained an adverse reaction found only mild symptom reactions of $38.5 \%$ in contrast to findings of Wang et al who found, from 84,928 observed patients, who underwent iodine contrast CT scans, found 545 adverse reactions $(0.6 \%)$ whereby of the total adverse reactions occurring 418 cases $(77 \%)$ of which were mild reactions and 116 cases $(21 \%)$ were moderate reactions, and the remaining $11(2 \%)$ cases were severe reactions requiring treat-ment. In the meantime, Gurses and Guler found that of 88 patients who underwent intravenous contrast CT 
scans found 13 patients (14.7\%) with mild and moderate reactions, but did not specify how large each reaction was. The reasons that can be stated from the differences of the research findings above are the demographic differences, as well as the dif-ferent types of contrast media used [6].

The results of this study shows that the subjects of the study experienced a positive crossover reac-tion, before contrast administration Iopamidol had a higher mean IgE level of $1270.79 \mathrm{mg} /$ $\mathrm{dl}$ compared with those not having an adverse reaction ie, $1174.90 \mathrm{mg} / \mathrm{dl}$ and after contrast administration Io-pamidol has a higher mean Ig E levels of $1507.96 \mathrm{mg} / \mathrm{dl}$ compared with those not experiencing an ad-verse reaction of $1325.88 \mathrm{mg} / \mathrm{dl}$. This is in line with a study by Gurses and Guler, which suggests that initial baseline igE measurements as baseline cannot be a prognostic factor for adverse reactions, however, adverse reactions that occur can be found at higher IgE levels after contrast. In this study found in respondents with positive adverse reaction, found increased serum IgE-levels greater than respondents who did not undergo adverse reactions [6].

\section{References}

[1] O. Goksel et al., "Hypersensitivity reactions to contrast media: prevalence, risk factors and the role of skin tests in diagnosis-a cross-sectional survey," International archives of allergy and immunology, vol. 155, no. 3, pp. 297-305, 2011.

[2] T. Miyauchi, T. Hirano, C. Ushiyama, Z. Ovary, K. Okumura, and H. Katayama, "Anaphylactic IgE and IgG1 production for hapten can be enhanced by contrast media," The British journal of radiology, vol. 69, no. 826, pp. 920-924, 1996.

[3] W. H. Bush and D. P. Swanson, "Acute reactions to intravascular contrast media: types, risk factors, recognition, and specific treatment.," AJR. American journal of roentgenology, vol. 157, no. 6, pp. 1153-1161, 1991.

[4] F. Dati and K. P. Ringel, "Reference values for serum IgE in healthy non-atopic children and adults," in Clinical chemistry, 1982, vol. 28, pp. 1556-1556.

[5] J. W. Dundee, J. P. H. Fee, J. R. McDonald, and R. S. J. Clarke, "FREQUENCY OF ATOPY AND ALELRGY IN AN ANAWESTHETIC PATIENT POPULATION," BJA: British Journal of Anaesthesia, vol. 50, no. 8, pp. 793-798, 1978.

[6] C. Gürses and A. Güler, "Correlation between the adverse reactions to intravenous iodinated contrast media and IgE levels," Diagnostic and Interventional Radiology, vol. 11, no. 2 , p. 74, 2005. 